\title{
Denver developmental screening test and preterm infants
}

\author{
A M Elliman, E M BRYAN, A D Elliman, P PALMER, AND L DUBOWITZ \\ Department of Paediatrics, Queen Charlotte's Hospital for Women and Department of Paediatrics and \\ Neonatal Medicine, Hammersmith Hospital, London
}

SUMmARY The results of Denver developmental screening test and Griffiths mental development scales examination performed on 198 preterm children during the first three years of life are compared. Using real age the former identified children with developmental delay, but labelled up to $42 \%$ of babies as having questionable or abnormal development. Using corrected age very few children showed less than normal development, and in the first year those whose Griffiths scales results showed delay were often assessed as normal by the Denver test. In view of its less satisfactory sensitivity and selectivity it is suggested that both age lines should be drawn when using the Denver test with preterm children so that undue anxiety can be allayed while appropriate action is taken to ensure adequate follow up.

In 1945 Gesell $^{1}$ concluded that when assessing the psychomotor development of preterm infants full allowance should be made for their prematurity. Twenty five years later the same conclusion was reached when a group of preterm babies tested at 40 weeks of age was found to have the same average developmental quotient (Gesell) as term, small for gestational age controls if allowance was made for prematurity, whereas their average development quotient was 11 points lower than the controls if no allowance was made. ${ }^{2}$ Hunt and colleagues, ${ }^{3}$ using the Bayley scales of mental development, ${ }^{4}$ also concluded that a better picture was obtained with corrected age but they were the first to point out that this may result in overcorrection in very preterm babies. Caputo and colleagues ${ }^{5}$ found an average of a seven point difference in development quotient $\left(\mathrm{Cattell}^{6}\right)$ at 1 year of age depending on whether or not an age correction was made. Similarly, Miller and colleagues ${ }^{7-9}$ found inappropriately high development quotients (Griffiths ${ }^{10}$ ) in a group of preterm babies ranging between 6 and 18 months when age was corrected for prematurity, while a more realistic picture was obtained when uncorrected age was used.

There is evidence that stimulation beneficially affects the rate at which babies develop. ${ }^{11} 12$ All preterm infants receive a certain amount of sensory input not shared by those whose intrauterine life continues to term. For instance they are exposed to a much wider range of auditory, tactile, visual, and olfactory stimuli. There is, therefore, good reason to expect a different timetable of development in these babies. It has been found that smiling in preterm infants is postponed by a factor equal to only half the deficit in gestational age. ${ }^{13}$

The importance of the result of a developmental test depends on the reason for administering it. A test used as a research tool or for the final assessment before recommending intervention must meet different requirements from one used in population screening. In the latter, it is particularly important that it is quick and easy to administer and interpret and that no deviant development present at the time is missed. Children with problems can then be referred for more detailed assessment and intervention as appropriate. The Denver developmental screening test ${ }^{14}$ meets most of the required criteria and is widely used for population screening. The purpose of this paper is to assess its usefulness in screening preterm infants.

\section{Methods}

All babies with birthweights between 501 and $2000 \mathrm{~g}$, whose gestation was less than 37 weeks, and who were born at Hammersmith Hospital or Queen Charlotte's Maternity Hospital in a one year period 
between June 1979 and May 1980 have been studied. Gestational age was determined using the Dubowitz assessment, ${ }^{15}$ mother's dates, and ultrasound.

As part of the study the children were given the Cardiff modification ${ }^{16}$ of the Denver developmental screening test by two of the authors (AME or EMB) at $6,9,12,18$, and 24 months of age. For each child two ages were calculated and the corresponding age lines were drawn on the chart representing the real and the corrected ages. The corrected age was obtained by subtracting the difference in weeks between the gestational age and term (40 weeks) from the real age. The children were examined in four developmental sectors-personal-social, fine motor, language, and gross motor, and were scored according to the revised method. ${ }^{17}$

Each sector was assessed as follows:

(a) The child performed tasks appropriate for his age, and showed up to one delay (inability to perform tasks which $90 \%$ of his age group can do)-normal.

(b) $\mathrm{He}$ could not perform any tasks appropriate for his age (that is which 25 to $90 \%$ of his age group can do) and had one delay-questionable.

(c) He had two or more delays-abnormal.

The overall test result was abnormal if the child had two or more abnormal or one abnormal and one or more questionable sectors. It was questionable if he had one abnormal or one or more questionable sectors. It was normal if all sectors were normal. The scoring procedure was carried out using both age lines; thus a result was obtained for real age and for corrected age at each assessment.

A number of children were also assessed using the Griffiths mental development scales ${ }^{1018}$ by a different observer (PP) on the same day as the Denver test. The order in which the tests were done varied. The Griffiths scales were used on the whole group by AME or EMB at 3 years. Development quotients were calculated using both real and corrected age. Correcting for prematurity caused two children's development quotient to rise from 76 to 80 , but none rose from below to above 70 . As Griffiths ${ }^{18}$ recommended that real age should be used, only these results are presented here. A lower limit of normal of 80 was taken, and those with development quotients between 70 and 79 were considered to have questionable development. Development quotients of 69 and below were considered abnormal.

\section{Results}

Of the 210 children in the study, $198(94 \%)$ were assessed at least once (196 at 2 years and 185 at 3 years). Eleven of the remaining 12 children were abroad. There were 100 boys and 98 girls. Gestation ranged from 26 to 36 weeks (mean 32 weeks) and birthweight from 730 to $2000 \mathrm{~g}$ (mean $1450 \mathrm{~g}$ ). One hundred and thirty nine were appropriate for gestational age and 59 small for gestational age.

Using real age at 6 months, $35 \%$ of the children had abnormal or questionable Denver test results, while this fell to five per cent when corrected age was used (Figure). This five per cent did not include any of the eight children whose Griffiths scales at 3 years gave a development quotient of less than 80 or any of the children with cerebral palsy.

At 9 months (Figure) a similar picture was obtained. The very high number of questionable results using real age largely reflects the babies' inability to sit unsupported, a milestone which $90 \%$ of Cardiff babies pass at $81 / 2$ months. Many of our preterm babies could not sit alone at 9 months.

The discrepancy between real age and corrected age results was still obvious at 2 years (Figure). Even at this age, twice as many children had questionable or abnormal results with real age as with corrected age. Of the 171 children seen on at least four occasions, 12 had questionable or abnormal Denver test results at all ages using real age (Table 1) and their mean 3 year development quotient was 74 . Sixty eight children had consistently normal Denver test results, and their mean 3 year development quotient was 105 . Using corrected age, only one child's Denver test results were consistently questionable or abnormal, and his 3

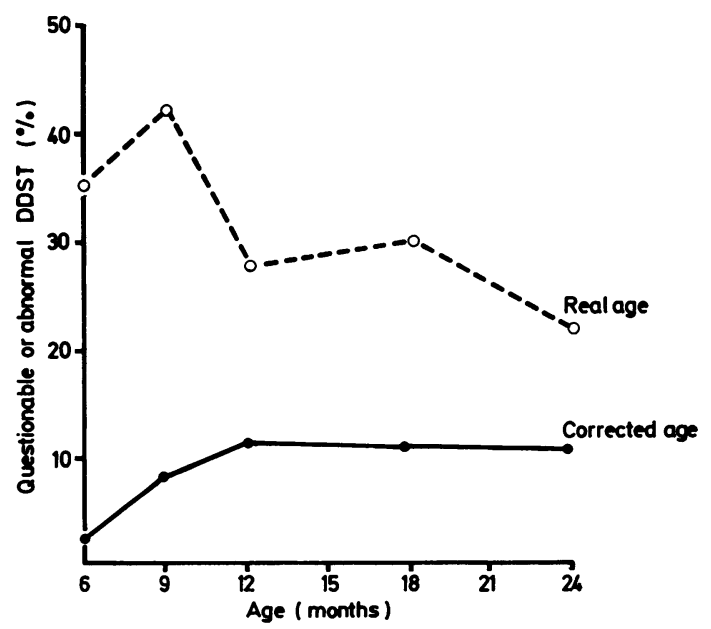

Figure Comparison of the percentage of children with questionable or abnormal Denver developmental screening test (DDST) results at real and corrected age from 6 to 24 months. 
year development quotient was 89; while the 143 children with consistently normal Denver test results had a mean development quotient of 104 .

All of the eight children with cerebral palsy had normal Denver test results on at least one occasion using corrected age, and two were consistently

Table 1 Comparison of serial Denver developmental screening test (DDST) results with 3 year Griffiths mental developmental scales (GMDS) in 171 children tested on at least four occasions

\begin{tabular}{|c|c|c|c|c|c|}
\hline \multicolumn{2}{|l|}{ Serial DDSTs } & \multicolumn{4}{|c|}{3 year GMDS } \\
\hline & No & Mean & Range & $S D$ & $\begin{array}{l}\text { No below } \\
80\end{array}$ \\
\hline
\end{tabular}

\begin{tabular}{|c|c|c|c|c|c|}
\hline \multicolumn{6}{|l|}{ Real age } \\
\hline $\begin{array}{l}\text { Consistently questionable } \\
\text { or abnormal }\end{array}$ & 12 & 74 & $47-112$ & 21 & 6 \\
\hline Consistently normal & 68 & 105 & $80-130$ & 11 & 0 \\
\hline Variable & 91 & 102 & $51-133$ & 15 & 2 \\
\hline \multicolumn{6}{|l|}{ Corrected age } \\
\hline $\begin{array}{l}\text { Consistently questionable } \\
\text { or abnormal }\end{array}$ & 1 & 89 & & & \\
\hline Consistently normal & 143 & 104 & $80-130$ & 12 & 0 \\
\hline Variable & 27 & 86 & $47-131$ & 20 & 8 \\
\hline
\end{tabular}

normal. Using real age none was consistently normal and only two were normal on any occasion.

Seventy one of the children $(34 \%)$ were given the Denver test and the Griffiths scales on the same day. At six months 52 children received both tests (Table 2). Using real age the Denver test identified 15 of 18 children with a development quotient of less than 80 as questionable or abnormal. In addition there were 13 false positives - that is children with development quotients of 80 or more whose Denver test results were questionable or abnormal. Using corrected age, two children (development quotients, 72 and 76) had questionable Denver test results and none was abnormal.

Of the 42 children given both tests at 9 months the real age Denver test again identified most of the children with low development quotients (Table 2) but there was a high false positive rate. Using corrected age only four of the 11 children with development quotients below 80 had questionable or abnormal results. The picture is similar at 12 months (Table 2). Using real age, the Denver test identified all five of the children with low development quotients but at the expense of nine false

Table 2 Comparison of Denver developmental screening test (DDST) and Griffiths mental development scales (GMDS) results obtained on the same day

\begin{tabular}{|c|c|c|c|c|c|c|}
\hline \multirow[t]{2}{*}{ Age (months) } & \multicolumn{3}{|l|}{$G M D S<80$} & \multicolumn{3}{|l|}{$G M D S \geqslant 80$} \\
\hline & $\begin{array}{l}\text { DDST } \\
\text { Questionablelabnormal }\end{array}$ & Normal & Total & $\begin{array}{l}\text { DDST } \\
\text { Questionablelahnormal }\end{array}$ & Normal & Total \\
\hline \multicolumn{7}{|l|}{$6(n=52)$} \\
\hline Real age & 15 & 3 & 18 & 13 & 21 & .34 \\
\hline $\begin{array}{l}\text { Corrected age } \\
(n=42)\end{array}$ & 2 & 16 & \multicolumn{3}{|c|}{$9(n=42)$} & 34 \\
\hline Real age & 10 & 1 & 11 & 8 & 23 & 31 \\
\hline Corrected age & 4 & 7 & 11 & 0 & 31 & 31 \\
\hline \multicolumn{7}{|l|}{$12(n=39)$} \\
\hline Real age & 5 & 0 & 5 & 9 & 25 & 34 \\
\hline Corrected age & 2 & 3 & 5 & 4 & 30 & 34 \\
\hline
\end{tabular}

Table 3 Comparison of Denver developmental screening test results (DDST) at 6, 9, and 12 months of age with Griffiths mental development scales (GMDS) results at 3 years

\begin{tabular}{|c|c|c|c|c|c|c|}
\hline \multirow[t]{2}{*}{ Age (months) } & \multicolumn{3}{|l|}{$G M D S<80$} & \multicolumn{3}{|l|}{$G M D S \geqslant 80$} \\
\hline & $\begin{array}{l}\text { DDST } \\
\text { Questionablelabnormal }\end{array}$ & Normal & Total & $\begin{array}{l}\text { DDST } \\
\text { Questionablelabnormal }\end{array}$ & Normal & Total \\
\hline \multicolumn{7}{|l|}{$6(n=150)$} \\
\hline Real age & 7 & 1 & 8 & 47 & 95 & 142 \\
\hline Corrected age & 0 & 8 & 8 & 9 & 133 & 142 \\
\hline \multicolumn{7}{|l|}{$9(n=125)$} \\
\hline Real age & 5 & 0 & 5 & 48 & 72 & 120 \\
\hline Corrected age & 3 & 2 & 5 & 5 & 115 & 120 \\
\hline \multicolumn{7}{|l|}{$12(n=152)$} \\
\hline Real age & 7 & 0 & 7 & 38 & 107 & 145 \\
\hline Corrected age & 7 & 0 & 7 & 10 & 135 & 145 \\
\hline
\end{tabular}


positives. When corrected age was used there were still some false positives, and three of the five children with low development quotients had normal Denver test results.

At 3 years the Griffiths scales were performed on 176 children. Eight children, four of whom had cerebral palsy, had a development quotient below 80. When these results were compared with the earlier Denver test results the screening test again identified the problem children when real age was used, but during the first year it was less satisfactory when corrected age was used (Table 3). Even children with obvious cerebral palsy were often undetected.

\section{Discussion}

There was a considerable discrepancy in the results of the Denver test depending on whether real age or corrected age was used. This discrepancy was still present at 2 years of age-twice as many children required further assessment using real age.

Comparison of the Denver developmental screening test results with the more detailed Griffiths scales development quotients obtained on the same day showed that using real age the screening test was good at identifying children with low development quotients, although there was a high false positive rate. Using corrected age, several of the children with low development quotients had normal Denver test results. When compared with the Griffiths scales assessments at 3 years the earlier real age Denver tests detected most of the children who were later to show developmental delay at the price of labelling as questionable or abnormal a large number who subsequently turned out to have development quotients within the normal range. Using corrected age, all the children who were later to have low development quotients had normal Denver test results at 6 months. It is possible that socioeconomic or racial factors may have had some effect on these findings and this area merits further study.

Using real age, the test was surprisingly good at identifying children with cerebral palsy, while using corrected age it was poor. Although the Denver test is not designed to identify such children, the ability to do so enhances its value.

These findings suggest that the Denver test becomes a more satisfactory instrument if no correction for prematurity is made. This does, however, result in up to $42 \%$ of the preterm population being referred for further assessment, although the recommended procedure of repeating the test before referring would reduce this number. About seven per cent of babies are preterm; thus at the most an additional two per cent of the total infant population would be referred for detailed assessments if preterm infants with developmental delay were to be identified and treated early. The inability of the corrected age Denver test to identify problem children makes it at best economically unjustifiable and at worst dangerous.

It has been shown that the early provision of home support such as advice on play and stimulation, speech therapy, or nursery placement increases the child's chances of achieving his full potential. ${ }^{11} 12$ All the babies, however, who were likely to benefit from such measures were identified in our study using the real age Denver test, but with a large number of false positives.

The Denver test is often used as a screening test but our work indicates that it may be unsuitable for preterm infants. If it is performed, we suggest drawing two age lines and scoring the baby's performance using both real and corrected age. It is safer to use real age which will alert the tester to the need for further assessment; the use of corrected age makes it possible to allay undue anxiety.

We thank Mrs Y Vinten for her help with many aspects of the study including keeping in touch with the families and preparing the manuscript and Drs Pamela Davies and David Harvey for their encouragement and helpful comments.

The study was supported by the Spastics Society.

\section{References}

1 Gesell A. The embryology of behaviour. New York: Harper. 1954.

2 Parmelee AH, Schulte FJ. Developmental testing of preterm and small for dates infants. Pediatrics 1970):45:21-8.

3 Hunt JV. Rhodes L. Mental development of preterm infants during the first year. Child Dev 1977:48:204-10.

${ }^{4}$ Bayley N. Bayley scales of mental and motor development. New York: The Psychological Corporation, 1969.

${ }^{5}$ Caputo DV, Goldstein KM, Taub HB. The development of prematurely born infants through middle childhood. In: Field TM, ed. Infants born at risk: behaviour and development. New York: S P Medical and Scientific Books, 1979:219-47.

- Cattell P. Infant intelligence scale. New York: The Psychological Corporation, 1940.

7 Palmer P, Dubowitz LMS, Levine MI, Dubowitz V. Developmental and neurological progress of preterm infants with intraventricular haemorrhage and ventricular dilatation. Arch Dis Child 1982;57:748-53.

* Palmer P, Dubowitz LMS, Verghote M. Dubowitz V. Neurological and neurobehavioural differences between preterm infants at term and full-term infants. Neuropediatrics 1982;13:183-9.

9 Miller G, Dubowitz LMS, Palmer P. Follow-up of preterm infants: is correction of the developmental quotient for prematurity helpful? Early Hum Dev 1984;9:137-44.

${ }^{10}$ Griffiths R. The abilities of babies. London: University of London Press, 1954

"Scarr-Salapatck S, Williams ML. The effects of early stimulation of low birthweight infants. Child Dev 1973;44:94-101.

12 Friedman SL, Chipman SF, Sefal JW, Cocking RR. Complementing the success of medical intervention. Semin Perinatol 1982;6:365-72.

${ }^{13}$ Foley H. When do preterm and light-for-dates babies s.nile? Dev Med Child Neurol 1977:19:757-60. 
14 Frankenberg WK, Dodds JB. Denver Developmental Screening Test. J Pediatr 1967:71:181-91.

15 Dubowitz LMS, Dubowitz V, Goldberg C. Clinical assessment of gestational age in the newborn infant. J Pediatr 1970;77:1-10.

${ }^{16}$ Bryant GM, Davies KJ, Newcombe RG. The Denver Developmental Screening Test. Achievements of test items in the first year of life by Denver and Cardiff infants. Dev Med Child Neurol 1974;16:475-84.

${ }^{17}$ Frankenberg WK, Goldstein AD, Camp BW. The revised
Denver Developmental Screening Test: its accuracy as a screening instrument. J Pediatr 1971;79:988-95.

${ }^{18}$ Griffiths R. The abilities of young children. London: Clinical Development Research Centre, 1970.

Correspondence to Dr A M Elliman, Queen Charlotte's Hospital for Women, London W6 0XG.

Received 6 August 1984

British Paediatric Association

\section{Annual meetings}

1985 16-20 April York University

1986 15-19 April York University

1987 7-11 April York University 